\title{
Tiempo de capuchinos en la Sagrada Familia
}

\author{
Francisco Martí Mateu
}

\section{Inicios}

Habiendo pasado los habitantes de Castellón unos años de incertidumbre e inestabilidad producidos por las sucesivas contiendas carlistas, en ese periodo se empiezan a trazar nuevas infraestructuras urbanísticas para crear un tejido urbano más amplio, y actual y adecuado a la nueva densidad de población que ya en 1883 superaba los 25000 habitantes. Este crecimiento demográfico indujo a la construcción de nuevos edificios para satisfacer la demanda social que se vivía. A finales del s. XIX, surge la necesidad también de construir nuevos lugares de culto, entre ellos estará la iglesia dels frares.

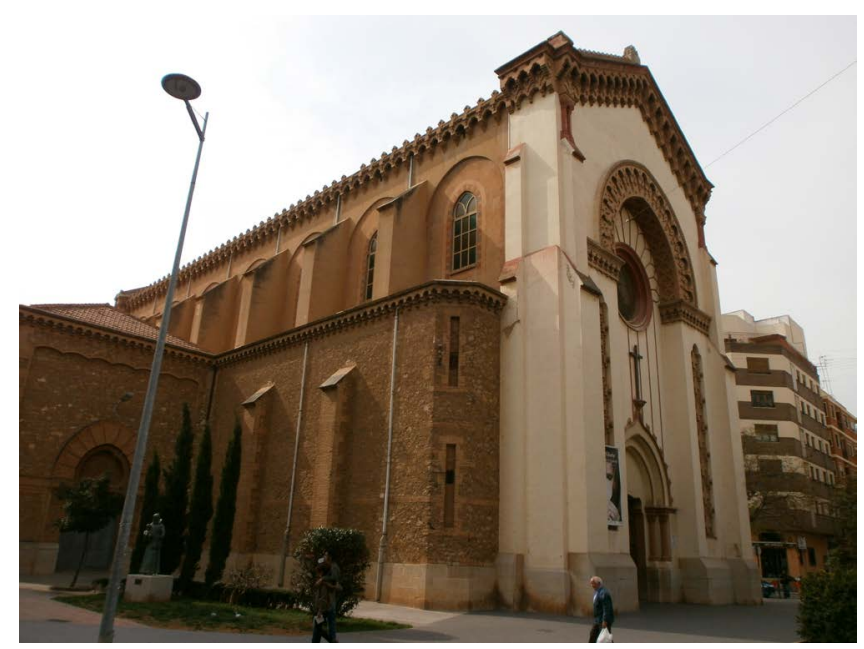

Figura 1. Iglesia de la Sagrada Familia, Castellón
Así indicaba el periódico Heraldo de Castellón el 15 de junio de 1896 la noticia de la colocación de la primera piedra:

A las $18 \mathrm{~h}$. de la tarde de ayer tuvo solemne realización de la anunciada fiesta de bendición y colocación de la primera piedra para la construcción en la Ronda Magdalena de la nueva iglesia que bajo la advocación de la Sagrada Familia levanta la piedad y el patriotismo del difunto Manuel Cardona Vives, hermano del ejemplar presbítero y castellonense ilustre Juan Bautista Cardona Vives (Prior de Lledó e hijo predilecto de Castellón).

De la comitiva invitada para asistir a esta ceremonia formaba parte el coronel Otumba, D. Vicente Villanueva, el Teniente Coronel D. Gaspar Tirado. Del elemento civil formaban parte los Sres. Cuenca, Echevarria, Matutano, Castells, Rafael Gaset, Dols, Guinot, Ros de Ursinos. En representación del clero el Sr. Arcipreste de Sta. María D. Tomas Castos, el vicario de la Sangre D. José Montoliu, etc.

La comitiva se dirigió al sitio del emplazamiento de las obras de la nueva iglesia por las calles de colón, en medio, S. Felix y Ribalta (actual Sagrada Familia) cuyos balcones estaban adornados con lujosas colgaduras. En la calle de Ribalta una nube de flores cayó sobre el prelado, que constataba a tales obsequios bendiciendo a las niñas que se los dispensaban. A la llegada del sitio señalado para la nueva iglesia la banda de regimiento militar saludo a las autoridades. 


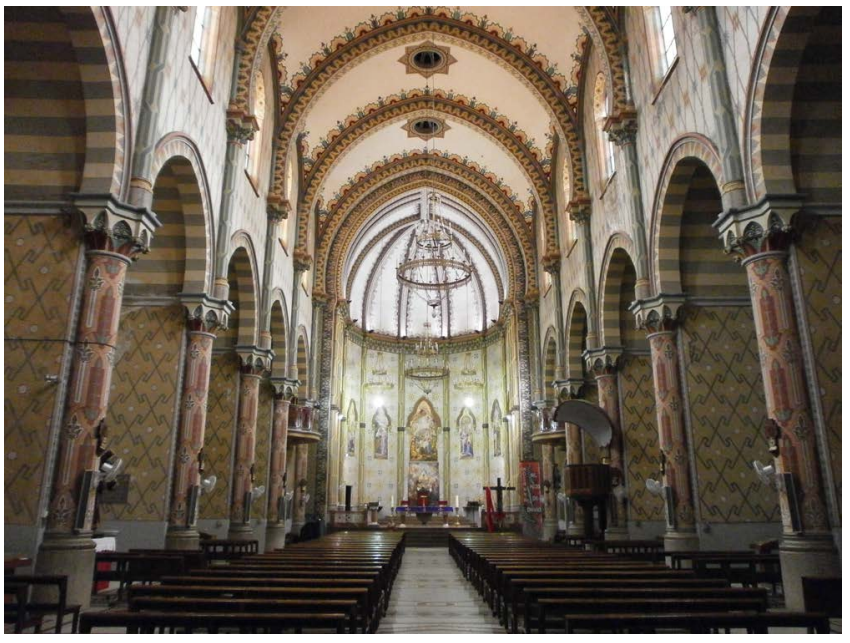

Figura 2. Nave principal

En un altar levantado por el adornista Soriano el Dr. Costa y el Vicario de la Sangre comenzaron las ceremonias propias; oraciones y salmos dirigidos primero a la cruz que marcaría el punto del emplazamiento del altar mayor de la iglesia.

Las obras terminaron el año 1900 bajo la dirección del arquitecto Godofredo Ros de Ursinos, por encargo de Juan Bautista Cardona Vives. El insigne sacerdote Cardona Vives era oriundo de Castellón de la Plana (1814-1890).

Los padres capuchinos se hicieron cargo de la iglesia el 22 de noviembre de 1903, siendo provisional reverendo fray Melchol de Benisa y comisionado fray Luís Amigó. Siguiendo el carisma de la orden menor de S. Francisco de Asís, se asentaron en la iglesia. Recibió llaves y, por tanto, fue el primer guardián fray Laureano de Masamagrell, que más tarde sería obispo de Segorbe. Cabe destacar, tal como consta en el libro de crónicas del convento, que en la primera colecta que se hizo se recaudaron dieciocho céntimos.

\section{Elementos arquitectónicos}

A partir de la segunda mitad del s. XIX comienza a aparecer una línea que mezcla formas provenientes de estilos anteriores, tales como el gótico, el románico o el mudéjar. En cierto modo, esta línea era consecuencia de ese romanticismo que exaltaba las culturas populares e históricas de las distintas comunidades. Dentro de este historicismo, el neogótico tendrá un papel destacado.

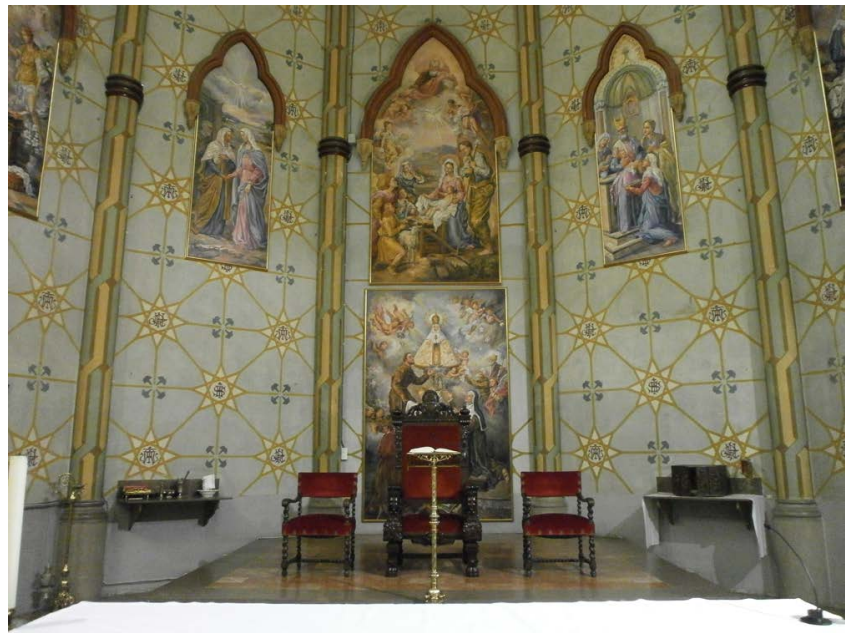

Figura 3. Interior del ábside

Ros de Ursinos, arquitecto fundamental en la Plana, formado en el espíritu de la renovación estilística, lleva a cabo inteligentes proyectos de construcción y remodelación urbana. Es el caso de la iglesia de la Sagrada Familia, de un estilo neorrománico con aires mudéjares en el exterior, donde aparecen arcos apuntados y decoración típica del modernismo floral en su nave interna, haciendo gala de un bien concebido eclecticismo.

La planta de la iglesia de la Sagrada Familia corresponde a una tipología de origen paleocristiano, inspirada en la idea de planta basilical pero con algunos toques arquitectónicos propios de la arquitectura industrial de principios del s. $\mathrm{xx}$.

El tamaño de la nave central indica la intención de albergar a multitud de fieles en su interior (característica propia de las iglesias paleocristianas frente a las de origen románico). Todo parece indicar que el arquitecto se inspiró en la tipología de planta basilical, un edificio de forma rectangular dividido en naves por columnas que solía tener una cabecera sobrelevada respecto al resto.

Sin embargo, introdujo nuevos conceptos constructivos asimilados de la arquitectura industrial. La división ficticia de tres cuerpos en la misma nave principal no se materializa mediante columnas, como es propio de la tipología citada, sino que es la misma estructura de muros portantes consecutivos la que, por su disposición, genera una serie de crujías en los laterales de la nave, que pueden llegar a recordar a las naves laterales de las basílicas. 


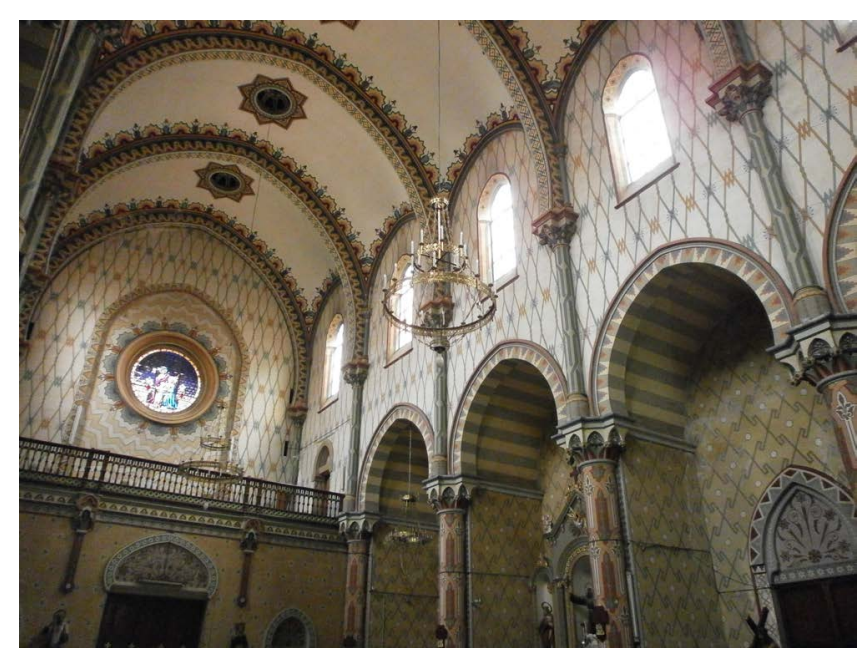

Figura 4. Vidrieras y rosetón

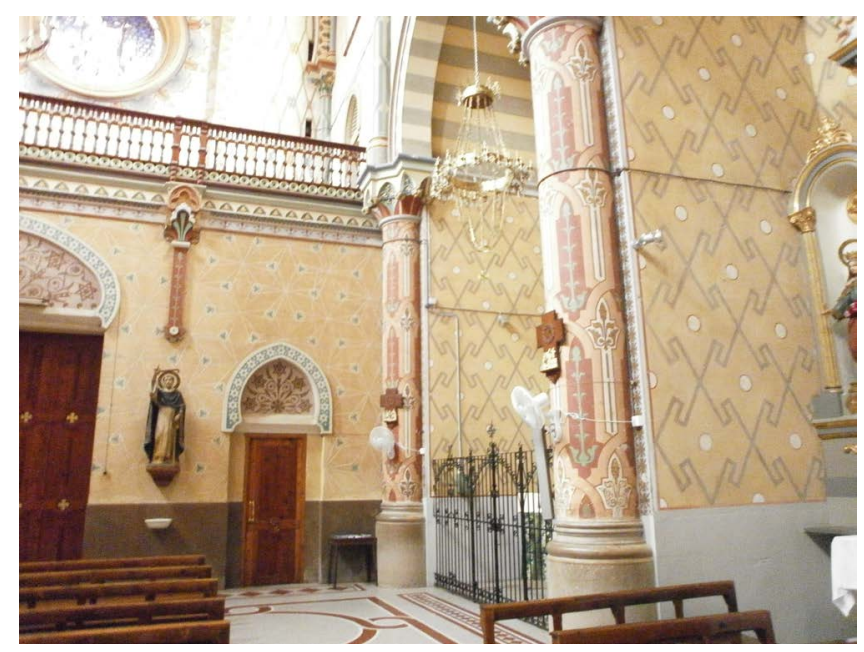

Figura 5. Coro y baptisterio

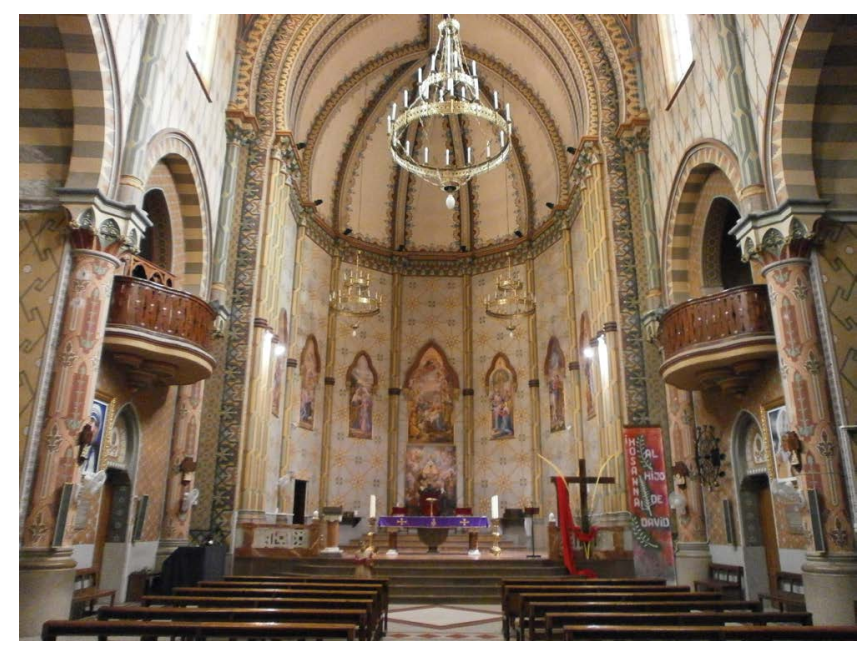

Figura 6. Altar mayor
En cuanto al presbiterio de las plantas, se construyó para esta iglesia un ábside de catorce lados en su recorrido completo y siete en su mitad. Otro aspecto que también se adapta a la planta basilical es el hecho de que está organizada en torno a un gran eje longitudinal que va a dirigir la mirada del fiel directamente y desde el principio hacia el altar.

La planta de la iglesia se divide en tres cuerpos longitudinales comunicados entre sí, una nave principal que destaca en dimensiones de planta y altura sobre las demás y dos naves laterales, la de la capilla de la comunión y la del teatro. Estas son del mismo tamaño pero con usos distintos: la primera sirve para celebraciones, siendo coronado el altar con una imagen de la coronación de la Virgen María, y la segunda sala sirve para las acciones evangelizadoras: catequesis, reuniones parroquiales, etc.

La fachada presenta una portada de carácter ecléctico, muy común a finales del s. XIX, con pinceladas de estilos mudéjares y góticos tardíos y con ciertas similitudes con la arquitectura religiosa empleada en el este de Europa. La misma se apoya sobre un zócalo de sillares de piedra de Borriol, a partir del cual emergen dos macizos en los laterales a modo de contrafuertes, cuya misión es sostener todo el peso de la misma, aunque toda ella constituye una parte esencial del sistema estructural por absorber todos los empujes longitudinales transmitidos por su gran masa.

La entrada principal está circundada en la parte superior por una serie de arcos apuntados apoyados sobre cuatro pilastras con capiteles decorados. En el remate del primer arco apuntado encontramos un pedestal que sirve de apoyo a una cruz latina de madera. Un rosetón de grandes dimensiones, con la imagen de la Sagrada Familia, corona el acceso. El conjunto es enmarcado por los citados macizos salientes a modo de una arcada monumental, dando fuerza a la entrada principal. Esta puerta conduce a un atrio que comunica, a través de dos puertas, directamente con la nave central y permite el acceso al coro a través de dos escaleras simétricas.

Las dos primeras imágenes que nos encontramos adosadas al muro que cierra la nave principal son la de san Francisco Javier y la de san Vicent. 
Una vez dentro, encontramos a ambos lados de la nave una serie continua de capillas en honor a santos y mártires de la iglesia católica comprendidas entre los muros.

En la primera de las capillas de la izquierda, se encuentra el baptisterio, de mármol, ubicado muy cerca de la entrada principal como es habitual por el significado de entrada que se le atribuye al bautismo. Una gran imagen de la Sagrada Familia adorna este importante espacio.

Las capillas que encontraremos en la izquierda serán, de este a oeste, las siguientes:

- Baptisterio.

- Capilla de san Francisco acompañado de santa Isabel, san Luis y la imagen sagrada de la Cueva Santa.

- Capilla de san Antonio de Padua acompañado por una imagen menor de san Antonio Abad.

Las capillas que encontraremos en la derecha serán, de este a oeste, las siguientes:

- Capilla de la Divina Pastora.

- Capilla del Sagrado Corazón.

- Capilla de la Inmaculada Concepción y santa Águeda.

- Capilla de los santos patrones de la ciudad: Verge de Lledó y san Cristóbal. Están acompañados por la imagen de santa Lucía y san Pascual.

- Cristo de Medinaceli y Cristo en la Cruz.

Sobre las capillas, en el nivel superior, existen ventanas de estilo mudéjar de forma rectangular rematadas con arcos apuntados de herradura, con un total de catorce vidrieras, siete a cada lado, en las cuales predominan los colores verde y ambarino.

En el primer nivel del presbiterio, se encuentra el altar mayor, construido con mármol blanco y mármol rojo, materiales predominantes. En la decoración del ábside predomina la policromía de los muros que sigue el mismo estilo y diseño que los del resto de la nave.

Como remate decorativo, en el año 2005 se incorporaron cinco lienzos trazados por el pintor Porcar Queral, cuyos motivos y formas se encontraban plasmados en el proyecto original pero que nunca se llegaron a realizar.

El acceso al campanario se encuentra tras el atrio de la nave y consta de una escalera de caracol que conduce a los dos niveles de la torre. El primero alberga un reloj que daba al exterior y el siguiente se encuentra al nivel del campanario, que consta de cuatro campanas. La decoración exterior sigue la misma tónica que el resto de la iglesia, a excepción de la cubierta: cúpula acebollada que, en este caso, cuenta con un material de cubrición metálico dispuesto a modo de escamas. La estructura que sustenta la cubierta está realizada íntegramente de madera.

\section{Aspectos socioreligiosos de la iglesia}

La iglesia ha sufrido todos los avatares sociopolíticos de la propia ciudad; en el libro de crónicas quedan reflejadas las altas y bajas de los frailes que ocuparon la parroquia. Hacemos especial hincapié en los padres que permanecieron en la misma durante la República o la guerra de 1936, años difíciles en los que incluso se realizaron mercados en la misma.

La iglesia deja de ser convento para pasar a ser parroquia el 1 de julio de 1940; esta distinción fomenta el servicio de comunidad al barrio. Tres años después, en 1943, empieza a publicarse la hoja parroquial.

En el verano del 2012, después de ciento nueve años de presencia franciscana en la parroquia, estos dejan la misma.

En la actualidad, els frares o la iglesia de la Sagrada Familia continúa acogiendo a los fieles que asisten a ella realizando una importante misión evangelizadora y social.

Cabe destacar la relevancia actual de la Cofradía del Cristo de Medinaceli o las celebraciones de las Fiestas de la calle del Raval. Durante el otoño, la comunidad celebra: la Balma, Sta. Bárbara, Verge de Lledó, san Félix y san Roc del Raval. 


\section{Referencias}

Comisió Organitzadora del Lxxv aniversari de la coronació de la Mare de Déu del Lledó (1999). Far del 3er Mil-leni: publicació extraordinària del Lxxv aniversari de la coronació de la Mare de Dèu del Lledó. Diputación de Castellón. Castellón.

Gines Herrera, F. y Pardo Llopis, X. (2011). Análisis arquitectónico de la Iglesia de la Sagrada Familia de Castellón. Universidad Politécnica de Valencia. Valencia.

Chust Calero, Manuel (dir.) (1992). Historia de Castellón. Levante de Castellón. Castellón.

Crónicas del convento de los padres capuchinos de Castellón (1903-1958). 